\title{
A Reliability Model for the Progression of Chronic Heart Failure
}

\author{
Meenaxi ${ }^{1}$, Dalip Singh ${ }^{2}$, Narender Singh ${ }^{3}$ \\ ${ }^{1,2,3}$ Department of Mathematics, M.D. University, Rohtak-124001, Haryana, India.
}

\begin{abstract}
The reliability of human beings and human activities are very important for the new complexity of life, work and medicine development. Markov models are well-established methods for estimating rates of transition between stages of chronic diseases. This paper is focused on the survival analysis of a heart patient with chronic heart failure due to reduced Ejection fraction. The objective of the paper is to describe the progression process of chronic heart failure $(\mathrm{CHF})$, estimate the mean time spent in each stage and to estimate the life expectancy. Mean Sojourn time, state probability distribution and expected number of patients in each state are also derived in this paper by using Kolmogorov differential equations.
\end{abstract}

Keywords: Chronic heart failure, Ejection fraction, CTMC, Kolmogorov differential equations, Life expectancy, Mean time to absorption

\section{INTRODUCTION}

Chronic heart failure is a developing illness which arising anatomical and physiological disorder of the heart in which incidence increases with person's age. Chronic heart failure is a very serious condition. Unfortunately it is incurable but it can be controlled. In chronic heart failure, our heart muscles get damaged and then heart becomes weak and does not pump properly. Chronic diseases have become a major cause of an increasingly frequent reason for the hospitalization of patients. Chronic diseases like heart diseases, stroke, cancer, diabetes etc. are the leading causes of morbidity and mortality, according to WHO, $60 \%$ of total premature deaths all over the world out of which $53 \%$ is in India, are from chronic diseases [9]. One of the strategies of defeating any chronic disease is to detect it as early as possible by insuring sufficient treatments of patients. As early as the chronic disease is detected, it is easier to keep the patients in their initial stages and delaying their transition to more critical stages using suitable treatments and appropriate lifestyle regime [2]. Multistate Markov models are well-accepted methods for evaluating rates of alteration between stages of chronic disease. Heart failure (HF) is a common clinical disorder that results from any structural or functional cardiac disorder that cheapens the ability of the ventricle to fill with or force out blood. HF may be caused by disease of the myocardium, pericardium, heart valves, vessels, or by metabolic disorders [10]. The cause of heart failure occurs in patients with a full range of left ventricle ejection fraction (LVEF). The Ejection Fraction is an amount to determine how well your heart is pumping out blood and in diagnosing and tracking heart failure. Ejection fraction is a key indicator of heart health. It is the percentage of blood that is pumped out of our heart by the left ventricle during each heartbeat. A healthy heart has an EF between 50 to $75 \%$; an EF below $50 \%$ means our heart is no more healthy/pumping well.

If anyone has an EF of less than $35 \%$, it causes a high risk of life- threatening irregular heartbeats that can cause sudden cardiac death.

There are many problems that can cause heart failure with reduced ejection fraction.

\begin{tabular}{|l|l|l|}
\hline Cause & What is it? & How it causes heart failure \\
\hline $\begin{array}{l}\text { Coronary artery } \\
\text { disease }\end{array}$ & $\begin{array}{l}\text { Blockages in } \\
\text { coronary arteries that } \\
\text { limit blood flow to } \\
\text { heart muscle }\end{array}$ & $\begin{array}{l}\text { 1. Damages heart failure } \\
\text { 2. Poor muscles ability to } \\
\text { pump }\end{array}$ \\
\hline Cardiomyopathy & $\begin{array}{l}\text { A diseases of heart } \\
\text { muscles }\end{array}$ & $\begin{array}{l}\text { Heart muscles getting } \\
\text { weakened and ultimately } \\
\text { pumping ability decreases }\end{array}$ \\
\hline $\begin{array}{l}\text { High blood } \\
\text { pressure }\end{array}$ & $\begin{array}{l}\text { Eminent pressure in } \\
\text { arteries }\end{array}$ & $\begin{array}{l}\text { Heart works slowly to } \\
\text { pump which weakens the } \\
\text { muscle }\end{array}$ \\
\hline Aortic stenosis & $\begin{array}{l}\text { Opening of aortic } \\
\text { valve is narrowed, } \\
\text { impaired blood flow }\end{array}$ & $\begin{array}{l}\text { Pumping ability decreases } \\
\text { due to narrowed valve } \\
\text { which weakens the muscle }\end{array}$ \\
\hline Arrhythmia & Irregular heart beat & $\begin{array}{l}\text { Due to irregular heart beat, } \\
\text { pumping capability reduces }\end{array}$ \\
\hline
\end{tabular}

Jacksons et al. (2003) presented a general hidden markov model for simultaneously estimating transition rates and probabilities of stage misclassification when diagnoses of disease stages are subject to error [3]. Later in 2007, shih and others proposed a method for estimating progression of a chronic disease with multistate properties- type 2 diabetes by unifying the prevalence pool concept with the Markov process model [4]. Begun et al. (2012) proposed a multistate continuous time non- homogeneous Markov model for describing patients with decreased renal function in order to quantify disease progression and its predictor covariates using observable data [5]. Anwar et al. (2014) presented a stochastic model for chronic kidney diseases [2]. The purpose of our paper is to develop a reliability model for the progression of chronic heart failure due to reduced ejection fraction. A multi state markov model is developed for survival analysis for patients suffering from chronic heart disease. Stochastic multistate or competing models, like Markov chains are the best suited to the analysis of such phenomena [9]. In this research paper two illness states, and one death states, viz. 
Death due to extremely low Ejection Fraction is considered. Accordingly, transition probabilities from one state to another are estimated.

\section{PROBLEM FORMULATION}

The reliability is the property to fulfil the required tasks within the given period for the given working conditions. Reliability theory contains reliability engineering disciplines, human and social reliability etc. Similarity to the engineering reliability, the human reliability can be defined as well as the probability that an individual will perform certain activity during a given period of time [12]. It is very important to solve the reliability problems even in the healthcare system. It is possible to study human reliability mainly using survival function for a population and thus predicting life spans for different groups, necessary for important social and economic decisions. Survival analysis is a branch of statistics which deals with the life expectancy of biotic structure. Survival analysis will be further applied in the case of ill persons, particularly for heart failure. Survival period (life expectancy) is, generally, the period of time ranging between the moment of birth and that of death. This type of survival period issued in studies on mortality or life expectancy [6]. When the Survival function $\mathrm{S}(\mathrm{t})$ is known, mean survival period $\mu$ can be estimated by the equation

$$
\mu=\int_{0}^{\infty} S(t) d t=\int_{0}^{\infty} t f(t) d t
$$

Continuous-time Markov chain, "CTMC" is appropriate to model CHF since the patient condition deterioration is continuous in time. A CTMC is said to be homogenous in time if the probability of going from one state to another is independent of the time on which the transition occurs. Homogeneity in time holds true for the process of CHF. Hence, one can assume that the finite homogenous continuous-time Markov chain may be an appropriate model of $\mathrm{CHF}$.

Table 1: Definition of the States of the CHF Model

\begin{tabular}{|c|c|c|}
\hline $\begin{array}{c}\text { State } \\
\text { No. }\end{array}$ & State Name & EF (\%) \\
\hline 1 & $\begin{array}{c}\text { Heart Failure with moderate } \\
\text { reduction in EF }\end{array}$ & $16-25 \%$ \\
\hline 2 & $\begin{array}{c}\text { Heart Failure with severe reduction } \\
\text { in EF }\end{array}$ & $<15 \%$ \\
\hline 3 & Death & - \\
\hline
\end{tabular}

(EF: Ejection Fraction)

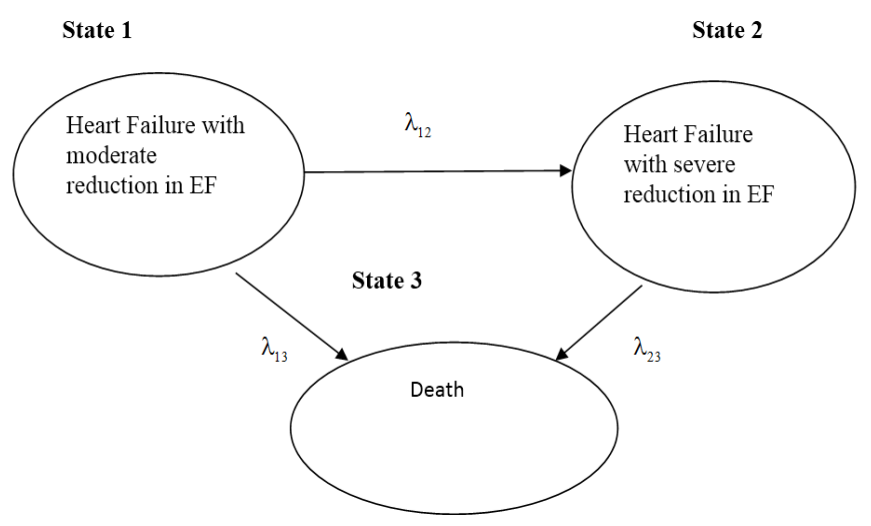

Figure 1.

Depending on the general illustrative model of CHF presented in fig1, the transition rate matrix is as follows:

$$
\mathrm{Q}=\left(\begin{array}{ccc}
-\lambda_{12}-\lambda_{13} & \lambda_{12} & \lambda_{13} \\
0 & -\lambda_{23} & \lambda_{23} \\
0 & 0 & 0
\end{array}\right)
$$

$\mathrm{Q}$ is a $3 \times 3$ matrix, its elements $\lambda_{\mathrm{ij}}$ are the istantantaneous rates of transition from one state to another. Sometimes matrix $\mathrm{Q}$ is called the generator matrix or the infinitesimal matrix. The elements of $\mathrm{Q}$ are the modal parameters which are population-specific and should be estimated when data is available using the appropriate method of estimation.

Kolmogorov's differential equations play central role in the treatment of markov processes in Continuous time.

The Kolmogorov equation is $\frac{\mathrm{d}}{\mathrm{dt}} \mathrm{P}(\mathrm{t})=\mathrm{P}(\mathrm{t}) \mathrm{Q}$ admits the unique solution $\mathrm{P}(\mathrm{t})=\exp (\mathrm{Qt})$ subject to the boundary condition $\mathrm{P}(0)=\mathrm{I}, \mathrm{Q}$ will have distinct eigen values and if $\mathrm{A}$ is the square matrix whose jth column is the right Eigen vector for $\rho_{j}$ (Eigen values), then

$$
\mathrm{P}(\mathrm{t})=\operatorname{A} \cdot \operatorname{diag}\left(\mathrm{e}^{\rho_{1} \mathrm{t}}, \mathrm{e}^{\rho_{2} \mathrm{t}}, \ldots \ldots .\right) \mathrm{A}^{-1}
$$

is the unique solution[7].

We have $\mathrm{Q}=\left(\begin{array}{ccc}-\lambda_{12}-\lambda_{13} & \lambda_{12} & \lambda_{13} \\ 0 & -\lambda_{23} & \lambda_{23} \\ 0 & 0 & 0\end{array}\right)$

where $\lambda_{i}=\sum_{j \neq i} \lambda_{i j}$ 
By using above equation (1), we get

$$
\begin{aligned}
& \mathrm{p}_{11}(\mathrm{t})=\mathrm{e}^{-\lambda_{1} \mathrm{t}} \\
& \mathrm{p}_{12}(\mathrm{t})=\frac{\lambda_{12}\left(\mathrm{e}^{\left.-\lambda 2^{\mathrm{t}}-\mathrm{e}^{-\lambda_{1} \mathrm{t}}\right)}\right.}{\lambda_{1}-\lambda_{2}} \\
& \mathrm{p}_{13}(\mathrm{t})=1-\mathrm{p}_{11}(\mathrm{t})-\mathrm{p}_{12}(\mathrm{t}) \\
& \mathrm{p}_{21}(\mathrm{t})=0 \\
& \mathrm{p}_{22}(\mathrm{t})=\mathrm{e}^{-\lambda_{2} \mathrm{t}} \\
& \mathrm{p}_{23}(\mathrm{t})=1-\mathrm{p}_{21}(\mathrm{t})-\mathrm{p}_{22}(\mathrm{t}) \\
& \mathrm{p}_{31}(\mathrm{t})=\mathrm{p}_{32}(\mathrm{t})=0 \\
& \mathrm{p}_{33}(\mathrm{t})=1
\end{aligned}
$$

\section{Mean Sojourn Time}

The mean sojourn time in state of a CTMC is calculated in terms of transition rates. Hence, we calculate that

$$
\begin{aligned}
& \mathrm{e}_{1}=\int_{0}^{\infty} \mathrm{e}^{-\left(\lambda_{12}+\lambda_{13}\right) \mathrm{t}} \mathrm{dt}=\frac{1}{\lambda_{12}+\lambda_{13}} \\
& \mathrm{e}_{2}=\int_{0}^{\infty} \mathrm{e}^{-\lambda_{23} \mathrm{t}} \mathrm{dt}=\frac{1}{\lambda_{23}}
\end{aligned}
$$

\section{State Probability Distribution}

It is important to estimate the state probability distribution in order to calculate the probability that the system will be in a particular state at a specific time point $t$, let us assume that the state probability distribution, sometimes known as the marginal distribution, of the process at time $t$ is $\Pi(\mathrm{t})$. For homogeneous CTMC, $\Pi(\mathrm{t})$ can be evaluated by solving the following system of differential equations

$\Pi^{\prime}(\mathrm{t})=\Pi(\mathrm{t}) \times \mathrm{Q}$ with the initial condition $\Pi(0)=\left(\Pi_{01}, \Pi_{02}, 0\right)$

Generally the solution of this system of equations depends on the form of $\mathrm{Q}$.

$$
\begin{aligned}
\Pi_{1}(\mathrm{t})= & \mathrm{e}^{-\lambda_{1} \mathrm{t}} \cdot \Pi_{01} \\
\Pi_{2}(\mathrm{t})= & \frac{\lambda_{12} \Pi_{01}}{\lambda_{2}-\lambda_{1}} \cdot \mathrm{e}^{-\lambda_{1} \mathrm{t}}+\Pi_{02} \mathrm{e}^{-\lambda_{2} \mathrm{t}}-\frac{\lambda_{12} \Pi_{01}}{\lambda_{2}-\lambda_{1}} \mathrm{e}^{-\lambda_{2} \mathrm{t}} \\
\Pi_{3}(\mathrm{t})= & \lambda_{13} \Pi_{01} \frac{\mathrm{e}^{-\lambda_{1} \mathrm{t}}}{-\lambda_{1}}+\frac{\lambda_{23} \lambda_{12} \cdot \Pi_{01}}{\lambda_{2}-\lambda_{1}} \cdot \frac{\mathrm{e}^{-\lambda_{1} \mathrm{t}}}{-\lambda_{1}} \\
& +\lambda_{23}\left(\Pi_{02}-\frac{\lambda_{12} \Pi_{01}}{\lambda_{2}-\lambda_{1}}\right) \frac{\mathrm{e}^{-\lambda_{2} \mathrm{t}}}{-\lambda_{2}}+\frac{\lambda_{13} \Pi_{01}}{\lambda_{1}}+\frac{\lambda_{23} \lambda_{12} \cdot \Pi_{01}}{\left(\lambda_{2}-\lambda_{1}\right) \lambda_{1}} \\
& +\frac{\lambda_{23}}{\lambda_{2}}\left(\Pi_{02}-\frac{\lambda_{12} \Pi_{01}}{\lambda_{2}-\lambda_{1}}\right)
\end{aligned}
$$

\section{Life Expectancy of a Heart patient}

Life expectancy of a Heart patient is equivalent to Mean time to absorption. We have 2 transient states and 1 super absorbing state such that the infinitesimal generator $\mathrm{Q}$ is a 3 $\times 3$ matrix which can be partitioned as follows

$\mathrm{Q}=\left(\begin{array}{cc}\mathrm{V} & \mathrm{R} \\ 0 & 0\end{array}\right)$ where $\mathrm{V}$ is the $2 \times 2$ infinitesimal generator among the transient states. Define a $2 \times 1$ vector $\mathrm{f}(\mathrm{t})=$ $\left[f_{1}(t), f_{2}(t)\right]^{T}$, where $f_{i}(s)$ is the time to absorption density from state $i$ such that $\mathrm{f}(\mathrm{t})=\mathrm{e}^{\mathrm{Vt}} \cdot \mathrm{R}$

Then matrix moment generating function is given by $\mathrm{M}(\mathrm{s})=$ $\int_{0}^{\infty} \mathrm{e}^{\mathrm{st}} \mathrm{f}(\mathrm{t}) \mathrm{dt}=-(\mathrm{V}+\mathrm{SI})^{-1} \mathrm{R}$ from which we can obtain the $\mathrm{r}^{\text {th }}$ moment $\mathrm{M}_{\mathrm{r}}=(-1)^{\mathrm{r}} \mathrm{r} ! \mathrm{V}^{-1} \mathrm{C}$

Therefore $\mathrm{M}_{1}=-\mathrm{V}^{-1} \mathrm{C}$, where $\mathrm{C}=1^{\mathrm{T}}$ is $2 \mathrm{X}_{1}$ column vector whose all entries are 1.

Now $\quad Q=\left(\begin{array}{ccc}-\left(\lambda_{12}+\lambda_{13}\right) & \lambda_{12} & \lambda_{13} \\ 0 & -\lambda_{23} & \lambda_{23} \\ 0 & 0 & 0\end{array}\right)$

Then

$$
\mathrm{V}=\left(\begin{array}{cc}
-\left(\lambda_{12}+\lambda_{13}\right) & \lambda_{12} \\
0 & -\lambda_{23}
\end{array}\right)
$$

and

$$
\mathrm{V}^{-1}=\frac{1}{\lambda_{23}\left(\lambda_{12}+\lambda_{13}\right)}\left(\begin{array}{cc}
-\lambda_{23} & -\lambda_{12} \\
0 & -\left(\lambda_{12}+\lambda_{13}\right)
\end{array}\right)
$$

implying that the mean time to absorption is 
$M_{1}=\left\lfloor\begin{array}{c}\frac{\lambda_{23}+\lambda_{12}}{\lambda_{23}\left(\lambda_{12}+\lambda_{13}\right)} \\ \frac{1}{\lambda_{23}}\end{array}\right\rfloor$

Therefore $\mathrm{E}\left(\tau_{\mathrm{i} 3}\right), \mathrm{i}=1,2$ can be interpreted as follows :

$\mathrm{E}\left(\tau_{13}\right)=\frac{\lambda_{23}+\lambda_{12}}{\lambda_{23}\left(\lambda_{12}+\lambda_{13}\right)}$ and $\mathrm{E}\left(\tau_{23}\right)=\frac{1}{\lambda_{23}}$. It is the life expectancy of a patient given that he observed his illness in state $\mathrm{i}$.

\section{Expected Number of Patients in Each State}

Let $\mathrm{m}(0)$ be the size of patients an initial time point $\mathrm{t}=0$. The initial size of patients

$\mathrm{m}(0)=\sum_{j=1}^{2} \operatorname{mj}(0)$, where $\mathrm{m}_{\mathrm{j}}(0)$ is the initial size of patients at state $\mathrm{j}$ given that there is $\mathrm{m}_{3}(0)=0$ patients at state 3 which is "Death" at the initial time point. Assuming that patients move independently within the states of the system and at the end of the time interval $(0, t)$, there is $\operatorname{Mj}(t)$ for $j=1,2$ patients in state $\mathrm{j}$ at time $\mathrm{t}$ and $\mathrm{M}_{3}(\mathrm{t})$ deaths at time $\mathrm{t}$. Depending on Chiang (1968) [8], then the expected number of patients in each state at time t can be computed directly as follows,

$\mathrm{E}\left\{\mathrm{Mj}(\mathrm{t}) \mid \mathrm{m}_{\mathrm{j}}(0)\right\}=\sum_{i=1}^{n-1} m_{i}(0) p_{i j}(t) \quad$ for $\mathrm{j}=1, \ldots, \mathrm{n}-1 \ldots \ldots .(*)$

and $E\left\{M_{3}(t) \mid m_{j}(0)\right\}=\sum_{i=1}^{n-1} m_{i}(0) p_{i 3}(t) \quad \forall j$

Equation (*) can be represented as follows

$\mathrm{E}\left\{\mathrm{M}_{1}(\mathrm{t}) \mid \mathrm{m}_{1}(0)\right\}=\mathrm{m}_{1}(0) \mathrm{p}_{11}(\mathrm{t})$

$E\left\{M_{2}(t) \mid m_{1}(0), m_{2}(0)\right\}==m_{1}(0) p_{12}(t)+m_{2}(0) p_{22}(t)$.

And the expected number of deaths will be

$$
\begin{aligned}
& \mathrm{E}\left\{\mathrm{M}_{3}(\mathrm{t}) \mid \mathrm{m}_{1}(0), \mathrm{m}_{2}(0), \mathrm{m}_{3}(0)\right\}= \\
& \quad=\mathrm{m}_{1}(0) \mathrm{p}_{13}(\mathrm{t})+\mathrm{m}_{2}(0) \mathrm{p}_{23}(\mathrm{t})+\mathrm{m}_{3}(0) \mathrm{p}_{33}(\mathrm{t})
\end{aligned}
$$

\section{Numerical Example}

We take transition rates as follows:

$$
\begin{aligned}
& \lambda_{12}=.26 \\
& \lambda_{13}=.03 \\
& \lambda_{23}=.17
\end{aligned}
$$

then the states of the system is defined in table 1 .
Now transition rate matrix becomes

$$
Q=\left(\begin{array}{ccc}
-0.29 & 0.26 & 0.03 \\
0 & -0.17 & 0.17 \\
0 & 0 & 0
\end{array}\right)
$$

We find the one-year transition probability matrix as follows:

$$
P(1)=\left(\begin{array}{ccc}
0.74 & 0.22 & 0.04 \\
0 & 0.84 & 0.16 \\
0 & 0 & 1
\end{array}\right)
$$

The mean time spent by a heart patient with reduced Ejection fraction in state 1 approximately equals 3 years and 5 months, while in state 2, 5 years and 10 months.

Assuming that the initial distribution of patients among the states of the system is $\Pi(0)=(0.4,0.6,0)$ then the distribution of patients after one year will be approximately as $\Pi(1)=(0.3,0.6,0.1)$. Also life expectancy of a patient is about 8 years 9 months given that he entered the system in state 1 , and for state 2 , life expectancy is 5 years 10 months.

Let $m(0)=850$ patients and divided among the 3 states of the system as $(675,175,0)$. Then the expected no. of patients in each state after 1 year is $(500,295,55)$.

\section{DISCUSSION}

Chronic diseases represent a medical condition to the health status of a patient to be characterized by number of illness states. Markov models provide a convenient framework for such type of analysis. Such models help to understand the mechanism of diseases and progression of diseases. Chronic diseases are the major causes of morbidity and mortality. It becomes a challenge which affects a substantial part of the population in developing countries. CTMC is important while dealing with progressive diseases. Kolmogorov differential equations play remarkable role.

Anthwal et al. presented a Mathematical model for genesis of Alzheimer disease through Markov Process [13]. Present paper deals with 3 state model in which last stage is death. We have presented illness state as heart failure with reduced ejection fraction. We presented explications of transition probability functions, life expectancy and mean time spent by patients in each state. We provide a particular case and use our results. Thus our main goal of this article has been to make awareness about these challenging problems.

\section{REFERENCES}

[1] Axente, N.L. Heart Failure Prognostic Model, PhD Thesis, Carol Davila University of Medicine and Pharmacy Bucharest, 2012.

[2] Anwar N, Mahmoud R, A Stochastic Model for the Progression of Chronic Kidney Disease, Journal of 
Engineering Research and Applications, Vol. 4, Issue 11( Version 1),November 2014, pp.08-19

[3] C.H.Jackson, D.L.Sharples, et al. Multistate Markov Models for disease progression with classification error, The Statistician, 52(2), 2003, 193-209, Doi: $10.1111 / 1467-9884.00351$

[4] H. Shih, P. Chou, C. Liu,T. Tung, Estimation of Progression of multi-state Chronic Disease using Markov model and Prevalence Pool Concept, BMC medical Informatics and Decision Making, 7, 2007, 34, Doi: 10.1186/1472-6947-7-34

[5] Begun, A.Icks, R.Waldeyer, S. Landwehr, M. Koch, G.Giani, Identification of a Multistate ContinuousTime Non homogeneous Markov Chain Model for Patients with Decreased Renal Function, Medical Decision Making, published online 28 December 2012, Doi: 10.1177/0272989X12466731

[6] Sinescu C; Tarcolea C; Paris AS; Axente NC; Human Reliability and Heart Failure Model, Advances in Environment, Biotechnology and Biomedicine, 2012, 305-310.

[7] Ira M. Longini, Jr., Michael G. Hudgens, Lecture Notes on Stochastic Processes in Biostatistics: Applications to Infectious Diseases, January 1, 2003

[8] L. Chiang, Introduction to Stochastic Processes in Biostatistics (1st edition, John Willy \& Sons, Inc., 1968).

[9] Grover G, Sreenivas V, Khanna S, Seth D, MultiState Markov Model: An Application to Liver Cirrhosis, Statistics in Transition new series, Autumn 2013 , Vol. 14, No. 3, pp. 429-442.

[10] Yancy CW, Jessup M, Bozkurt B, et al. 2013 ACCF/AHA guideline for the management of heart failure: executive summary: a report of the American College of Cardiology Foundation/American Heart Association Task Force on practice guidelines., 2013, Vol 62, No. 16, 1495-539.

[11] Curtis JP; Sokol SI; Wang Y; Rathore SS; Dennis T; Jadbabaie F; Portnay EL; Marshalko SJ; Radford MJ; Krumholz HM; The Association of Left Ventricular Ejection Fraction, Mortality, and cause of Death in stable outpatients with Heart Failure, journal of the American College of Cardiology, 2003, vol 42, no. 4, 736-42.

[12] Hollnagel, E., Cognitive Reliability and Error Analysis Method (CREAM) Oxford: Elsevier Science Ltd., 1998

[13] Anthwal P, Goal N, Ram M, Thapliyal A, Mathematical modelling for genesis of Alzheimer disease through Markov process, International journal of Pharm Tech Research, 2016, vol 9, No. 7,189-199. 